\title{
Countermeasure against Increase of Heavy Rainfall
}

\author{
Tsubasa HASHIMOTO, Hiroyuki SHIGEMURA, Toshihiro YOKOTA \\ Water Quality Control Department, National Institute for Land and Infrastructure Management \\ (NILIM), Asahi 1, Tsukuba, 305-0804, Japan
}

\begin{abstract}
In recent years, heavy rainfall over $50 \mathrm{~mm} / \mathrm{h}$ and heavy rainfall concentrated into short time span on the order of $10 \mathrm{~min}$ have occurred more frequently in Japan, owing to the effects of phenomena such as climate change. This report describes the result of simulation using simulated drainage zones to examine the specific countermeasures that are suitable for each district. We consider it important to increase the inundation control quantity across the entire area (1) using peak reduction storage infrastructure for areas at the branch line drainage zone level and for short-duration heavy rainfall, and (2) using a combination of inundation countermeasures including downflow infrastructure and storage infrastructure to upgrade the entire runoff area for heavy rainfall that continues for a long duration in areas at the main line drainage zone level. This paper also reports on progress in collecting case examples on facilities that utilized stormwater in each local government. These case examples are being collected as a resource for promoting the improvement of stormwater storage infrastructure and the effective utilization of water resources in the future.
\end{abstract}

Keywords: heavy rainfall, inundation countermeasure, inundation simulation, stormwater utilization

\section{INTRODUCTION}

In Tokyo, it is reported that hourly heavy rainfall around the 1940's was even more frequent than in the 1990's (Kanae et al., 2004). On the other hand, on a national basis, the numbers of days when daily rainfall reaches $100 \mathrm{~mm}$ and days when daily rainfall reaches $200 \mathrm{~mm}$ have both significantly increased over the long term. And it is reported that during the past 30 years, the number of days when daily rainfall reaches $100 \mathrm{~mm}$ and the number of days when daily rainfall reaches $200 \mathrm{~mm}$ were 1.2 times and 1.4 times, respectively, more frequent than they were in the first 30 years of the $20^{\text {th }}$ century (JMA, 2007). Frequency of rainfall over $50 \mathrm{~mm} / \mathrm{h}$ is shown in Fig. 1. In FY 2004, yearly frequency recorded an all-time high since observations began. Although there is regional difference, in recent years, heavy rainfall over $50 \mathrm{~mm} / \mathrm{h}$ and heavy rainfall concentrated into short time span on the order of $10 \mathrm{~min}$ have occurred more frequently in Japan, owing to the effects of phenomena such as climate change. It is also reported that during a long period of 100 years, although regionally scattered, future change of annual maximum 1-day, 2-day, and 3-day rainfall will have an average increase of about 1.3 times the present levels (Kashiwai et al., 2008). In the Kanto district, the increasing trend of heavy rainfall is prominent (Abeyama et al., 2010).

Although various cities have been developing inundation countermeasures to prevent inundation damage, looking at the long term, the characteristics of rainfall are changing, and existing inundation prevention measures alone might not be able to handle 1-in-5-year or 1-in-10-year heavy rainfall. It is reported that the number of inundation damage by heavy rainfall concentrated into short time spans on the order of $10 \mathrm{~min}$ is increasing (Abe et al., 2011).

Address correspondence to Tsubasa Hashimoto, Water Quality Control Department, National Institute for Land and Infrastructure Management, Email: gesuidou@nilim.go.jp

Received April 15, 2013, Accepted October 4, 2013. 
In each city, it is necessary to upgrade the countermeasure against the increase of heavy rainfall efficiently. In our previous report (Hashimoto et al., 2012), we investigated the changing trends in the occurrence of heavy rainfall over the medium and long term using past rainfall information. We inferred that the intensity of 1-in-5-year and 1-in-10-year rainfall events within 10- and 60-min periods might increase throughout Japan by a maximum factor of approximately 1.3 to 1.4 (95th percentile) over present values in the next 50 years. On this basis, we performed inundation simulations for three districts. When we evaluated the effect of increasing heavy rainfall on existing inundation countermeasures, we observed a predicted scenario in which the area inundated to a depth over $0.2 \mathrm{~m}$ increased (Table 1). The results also suggest that inundation countermeasures are needed to address the specific cause of inundation in an area; for example, if stormwater drainage capacity is insufficient over a wide area or if local inundation occurs due to the limited drainage capacity of a branch line. This report describes the results of simulations using simulated drainage zones to investigate the validity of the above evaluation results and to examine the specific countermeasures that are suitable for each district.

This paper also reports on progress in collecting cases of facilities that utilized stormwater in each local government. These cases are being collected as a resource for promoting the improvement of stormwater storage infrastructure and the effective utilization of water resources in the future, as was introduced in our previous report (Hashimoto et al., 2012).

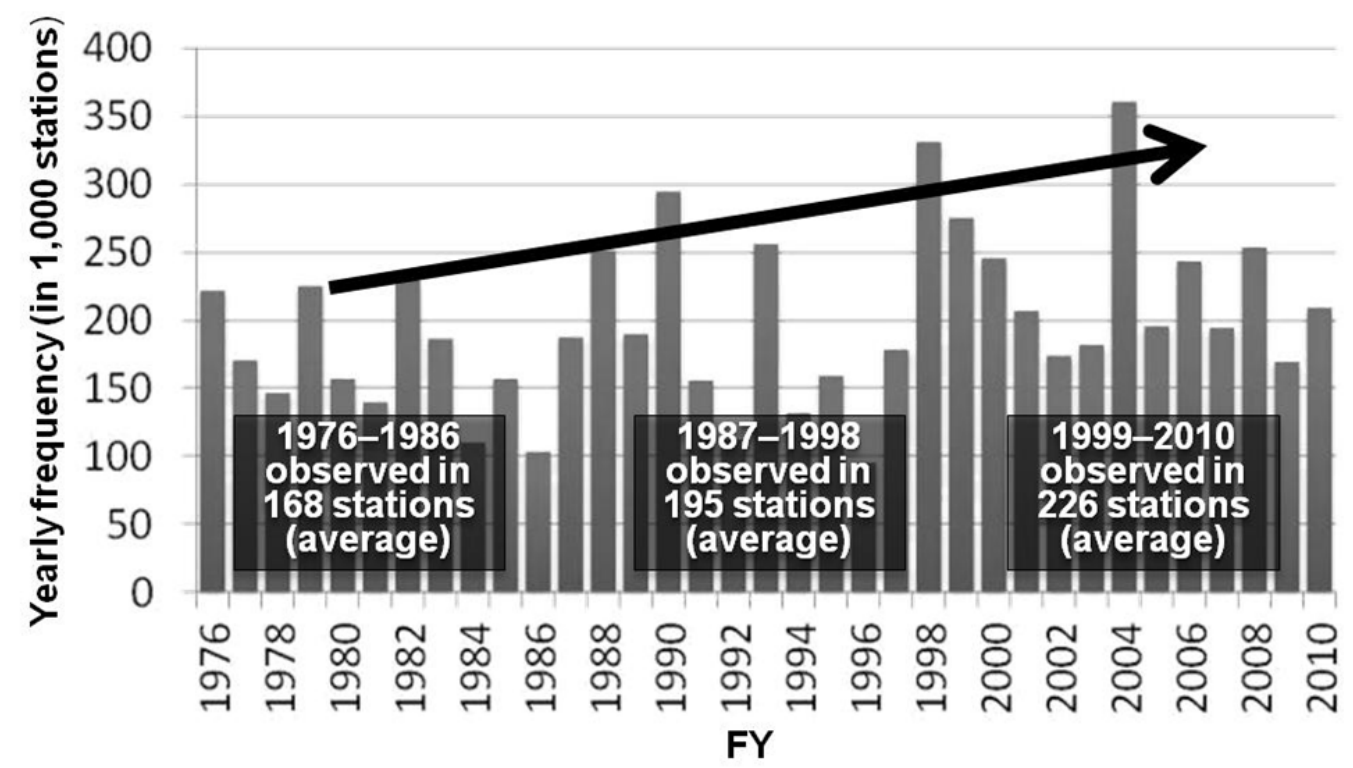

Fig. 1 - Frequency of rainfall over $50 \mathrm{~mm} / \mathrm{h}$ in Japan (from Japan Meteorological Agency data). 
Table 1 - Inundation simulation results in areas having different characteristics (Hashimoto et al., 2012).

\begin{tabular}{|c|c|c|c|c|c|}
\hline \multicolumn{3}{|c|}{ District name } & District $\mathrm{X}$ & District Y & District Z \\
\hline \multicolumn{3}{|c|}{ Drainage method } & Combined & Separate & Combined \\
\hline \multicolumn{3}{|c|}{ Area of drainage district $\left(10^{4} \mathrm{~m}^{2}\right)$} & 3,350 & 62 & 1,900 \\
\hline \multicolumn{3}{|c|}{ Runoff coefficient } & 0.45 & 0.60 & 0.82 \\
\hline \multirow{2}{*}{$\begin{array}{l}\text { Rainfall } \\
\text { simulated }\end{array}$} & \multicolumn{2}{|c|}{ 60-min rainfall intensity $(\mathrm{mm} / \mathrm{h})$} & 34.3 & 50.0 & 53.4 \\
\hline & \multicolumn{2}{|c|}{ 10-min rainfall intensity $(\mathrm{mm} / \mathrm{h})$} & 87.1 & 109.5 & 114.6 \\
\hline \multicolumn{3}{|c|}{ Case example of inundation countermeasures } & $\begin{array}{l}\text { Down-flow } \\
\text { pipes }\end{array}$ & $\begin{array}{l}\text { Storage } \\
\text { ponds }\end{array}$ & $\begin{array}{l}\text { Storage } \\
\text { pipes }\end{array}$ \\
\hline \multirow{6}{*}{$\begin{array}{l}\text { Rainfall } \\
\text { patterns }\end{array}$} & \multirow{2}{*}{$\begin{array}{l}\text { Increase of } \\
10 \text {-min rainfall } \\
\text { intensity }\end{array}$} & $\begin{array}{l}\text { Increase rate of inundation } \\
\text { area (inundation depth over } \\
0.2 \mathrm{~m} \text { )* }\end{array}$ & $0.7 \%$ & $6 \%$ & $0.4 \%$ \\
\hline & & Main region of inundation & - & Upstream & - \\
\hline & \multirow[t]{2}{*}{$\begin{array}{l}\text { Increase of } \\
60 \text {-min rainfall } \\
\text { intensity }\end{array}$} & $\begin{array}{l}\text { Increase rate of inundation } \\
\text { area (inundation depth over } \\
0.2 \mathrm{~m} \text { )* }\end{array}$ & $7 \%$ & $0 \%$ & $7 \%$ \\
\hline & & Main region of inundation & Midstream & - & Overall \\
\hline & \multirow{2}{*}{$\begin{array}{l}\text { Increase of } 10- \\
\text { and } 60-\text { min } \\
\text { rainfall } \\
\text { intensity }\end{array}$} & $\begin{array}{l}\text { Increase rate of inundation } \\
\text { area (inundation depth over } \\
0.2 \mathrm{~m} \text { )* }\end{array}$ & $9 \%$ & $6 \%$ & $4 \%$ \\
\hline & & Main region of inundation & Midstream & $\begin{array}{l}\text { Upstream, } \\
\text { Midstream }\end{array}$ & Overall \\
\hline
\end{tabular}

*(Increase rate of inundation area) $=($ (Inundation area by each rainfall pattern $)-($ Inundation area by standard rainfall pattern)) / (Area of drainage district)

\section{CASE STUDY USING SIMULATED DRAINAGE ZONES Selection of simulated drainage zones}

Two simulated drainage zones having different drainage areas were used (Fig. 2). Drainage zone I was assumed to be a wide-area zone containing a main line, and drainage zone II was assumed to be a local zone containing a branch line only. In order to put the feature of each rainfall scenario in target inundation control quantity, we set the simulated drainage zones having different flow time.

\section{Selection of rainfall scenarios}

The following rainfall scenarios (Table 2): scenario A, in which the rainfall intensity over a 10 -min period was increased by $30 \%$ over the standard rainfall intensity that was set according to the local government cases $(124.5 \mathrm{~mm} / \mathrm{h}$ over a $10-\mathrm{min}$ period and 59.0 $\mathrm{mm} / \mathrm{h}$ over a 60 -min period); scenario $\mathrm{B}$, in which the rainfall intensity over a 60 -min period was increased by $30 \%$; and scenario $C$, in which the rainfall intensity over $10-$ and 60 -min periods was increased by $30 \%$, were assumed. Since the rainfall patterns here are merely simulated rainfall, when setting the coefficients in the rainfall intensity equation, a characteristic coefficient method was used in which the rainfall intensity curve was set from only the 10 -min and 60 -min rainfall.

\section{Selection of target inundation control quantity}

For the target inundation control quantity, the amount of stormwater runoff under each rainfall scenario was calculated by the time area method. The amount of stormwater runoff that exceeded the permitted amount of outflow set separately for each drainage zone $\left(24 \mathrm{~m}^{3} / \mathrm{s}\right.$ for drainage zone I and $0.44 \mathrm{~m}^{3} / \mathrm{s}$ for drainage zone II) was taken to be the inundation control quantity. 


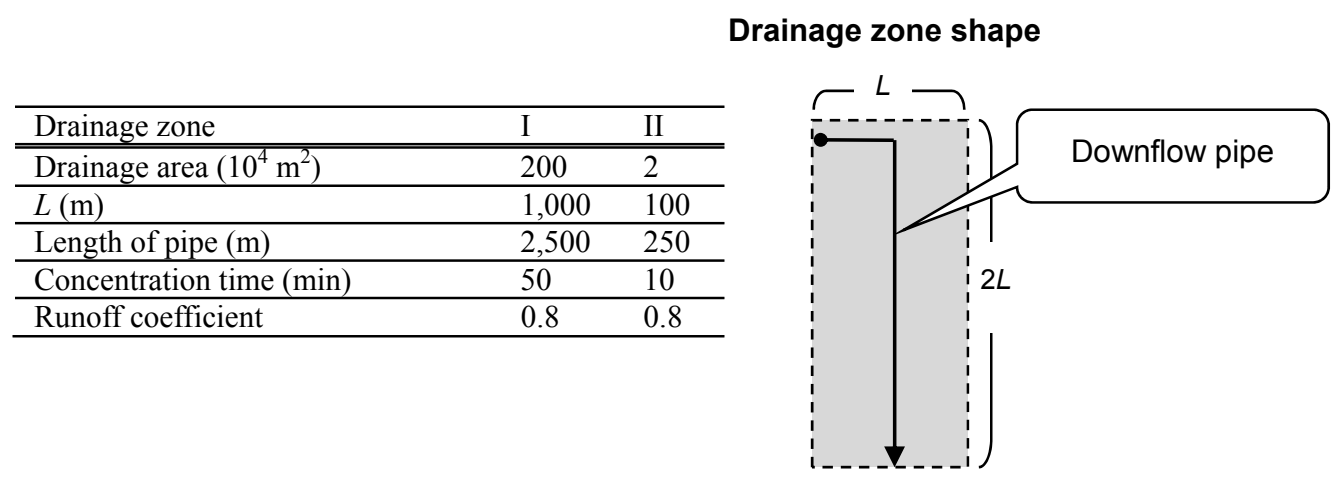

Fig. 2 - Simulated drainage zones.

Table 2 - Rainfall scenario.

\begin{tabular}{lll}
\hline Scenario & $10-$ min Rainfall Intensity $(\mathrm{mm} / \mathrm{h})$ & $60-$ min Rainfall Intensity $(\mathrm{mm} / \mathrm{h})$ \\
\hline \hline Standard rainfall intensity & 124.5 & 59.0 \\
\hline Rainfall scenario A & 161.8 & 59.0 \\
\hline Rainfall scenario B & 124.5 & 76.7 \\
\hline Rainfall scenario C & 161.8 & 76.7 \\
\hline
\end{tabular}

\section{Selection of types of inundation countermeasures}

The inundation countermeasures considered were downflow infrastructure (downflow pipes and pumping equipment), stormwater storage pipes, and rainfall infiltration facilities. The drainage zones were assumed to be pumped drainage zones with the pumping equipment installed at the most downstream end of the downflow pipes.

The mean infiltration rate of rainfall infiltration facilities was set by referring to the local government cases. It was set that the mean infiltration rate was $6 \mathrm{~mm} / \mathrm{h}$ when the area fraction of installed infiltration infrastructure was $100 \%$. The specifications of the stormwater storage pipe infrastructure were set based on the shield tunneling method. When upgrading the stormwater storage pipe infrastructure, the shield tunneling method is often used. For the downflow pipes, the drainage zones were divided into four blocks having equal drainage areas. The length of pipe was $2 L / 5$ for the block that was uppermost in the flow while $L / 5$ for the other blocks. The inundation control quantity was calculated at the downflow end of each block, and the pipe diameter (fixed pipe diameter within each block) was set based on the inundation control quantity.

The inundation control quantity of each countermeasure is indicated in the following section.

\section{Examined cases}

A total of 120 cases consisting of combinations of the simulated drainage zones (2 cases) in Fig. 2, rainfall scenarios (3 cases) presented in Table 2 and the 20 cases in Table 3 were examined. In terms of the method for upgrading inundation countermeasures, the inundation control quantity was obtained by first placing priority on upgrading infiltration infrastructure and then upgrading storage pipes and downflow pipes in the proportions shown in Table 3 such that the necessary value was obtained. When the downflow pipe upgrade ratio was $25 \%$ to $100 \%$, the pumping equipment was set to be upgraded by the same amount. 
Table 3 - Examined cases.

\begin{tabular}{ll}
\hline Scenario & Details \\
\hline \hline \multirow{3}{*}{$\begin{array}{l}\text { Installation of infiltration } \\
\text { infrastructure }\end{array}$} & Area fraction: $75 \%$ \\
\cline { 2 - 2 } & Area fraction: $50 \%$ \\
\cline { 2 - 2 } & Area fraction: $25 \%$ \\
\cline { 2 - 2 } & Area fraction: $0 \%$ \\
\hline \multirow{3}{*}{$\begin{array}{l}\text { Installation of storage pipes } \\
\text { and downflow pipes }\end{array}$} & Storage pipe upgrade fraction: $100 \%$, downflow pipe upgrade fraction: $0 \%$ \\
\cline { 2 - 2 } & Storage pipe upgrade fraction: $75 \%$, downflow pipe upgrade fraction: $25 \%$ \\
\cline { 2 - 2 } & Storage pipe upgrade fraction: $50 \%$, downflow pipe upgrade fraction: $50 \%$ \\
\cline { 2 - 2 } & Storage pipe upgrade fraction: $25 \%$, downflow pipe upgrade fraction: $75 \%$ \\
\hline
\end{tabular}

\section{Evaluation method}

The evaluation method is described below.

1) Calculation of the potential inundation control quantity:

The inundation control quantity was calculated for each of the inundation countermeasures in each scenario based on the concepts described in the previous sections.

2) Calculation of the economic potential:

The cost of upgrading the inundation countermeasures was calculated by multiplying the inundation control quantity by the unit upgrade cost set according to the reference values and local government cases. For example, the unit upgrade cost of storage pipes was $210,000 \mathrm{yen} / \mathrm{m}^{3}$. This data was obtained from hearing about the plan of inundation countermeasures in one local government.

$($ Indicator value of economic potential $)=$

$$
\sum\{(\text { Inundation control quantity) (Unit upgrade cost) }\}
$$

3) Calculation of the timing potential:

The time to upgrade the inundation countermeasures was calculated based on the inundation control quantity and the speed of upgrades set according to the reference values and local government cases. For example, the speed of upgrades per year of storage pipes was $2,000 \mathrm{~m}^{3}$. This data was obtained from hearing about the plan of inundation countermeasures in one local government.

$$
\begin{aligned}
& \text { (Indicator value of timing potential })= \\
& \left.\qquad \sum\{\text { (Inundation control quantity) (Unit upgrade speed })\right\}
\end{aligned}
$$

4) Overall evaluation:

Indicator values of the economic potential and timing potential were quantified. More specifically, the cost per cubic meter of inundation countermeasures was used as the indicator value of economic potential and the time to complete inundation countermeasures was used as the indicator value of timing potential. Since these indicators have different units, the scores were normalized using the following equation for each rainfall scenario and water drainage zone. 
$($ Standard score $)=\sum\{1-($ Indicator value $) /$

(Worst indicator value from among the 20 cases in Table 3 ) $\}$

The sum of the normalized scores for the economic potential and timing potential is called the standard score, and overall evaluation was performed by comparing this metric. As the value of the standard score becomes larger, the effectiveness of the upgrades is evaluated more highly.

\section{Evaluation results}

The overall evaluation results for drainage zone I for the case where the area fraction of installed infiltration infrastructure was $25 \%$ are shown in Fig. 3. In this case, the pumping equipment was relatively expensive, and from the standardized scores, the effectiveness of the upgrades were evaluated highly for storage pipe upgrade fraction of $100 \%$ and poorly for storage pipe upgrade fraction of $75 \%$. Furthermore, although the storage pipe upgrade fraction of $100 \%$ had significantly high effectiveness in rainfall scenario A, the difference between storage pipe upgrade fractions of $100 \%$ and $0 \%$ was relatively small in rainfall scenarios $\mathrm{B}$ and $\mathrm{C}$. This was because the inundation control quantity that is required in rainfall scenarios $\mathrm{B}$ and $\mathrm{C}$ is large, and if the upgrade is implemented using storage pipes for $100 \%$ of the upgrade fraction, relatively large storage infrastructure becomes necessary, and the difference from upgrading the downflow infrastructure (downflow pipes + pumping equipment) becomes smaller in terms of cost and construction time. Table 4 shows the standard score of 120 cases. In drainage zone II which has a small drainage area, the score for the storage pipe upgrade fraction of $100 \%$ is much larger than that in the other drainage zones in all cases. Thus, the peak reduction using storage pipes is expected to be effective.

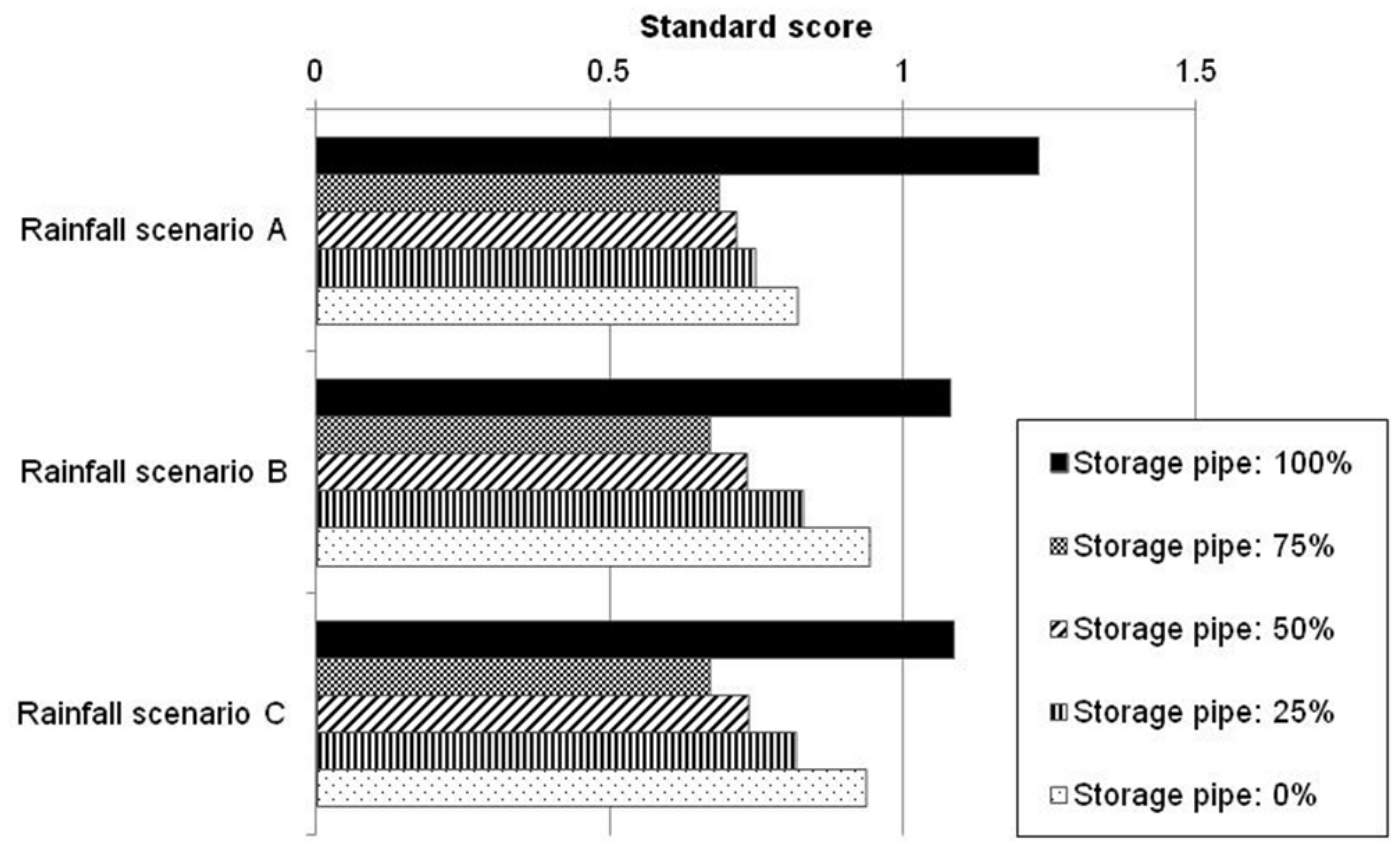

Fig. 3 - Standard score (drainage zone I) (area fraction of installed infiltration infrastructure: $25 \%$ ). 
Table 4 - Standard score of 120 cases.

\begin{tabular}{|c|c|c|c|c|c|c|c|c|c|}
\hline \multicolumn{2}{|l|}{ Drainage Zone } & \multicolumn{4}{|c|}{ Drainage Zone I } & \multicolumn{4}{|c|}{ Drainage Zone II } \\
\hline Area fraction of infi & infrastructure installation & $0 \%$ & $25 \%$ & $50 \%$ & $75 \%$ & $0 \%$ & $25 \%$ & $50 \%$ & $75 \%$ \\
\hline \multirow{5}{*}{ Rainfall scenario A } & Storage pipe: $100 \%$ & 1.515 & 1.233 & 0.836 & $\overline{0.444}$ & 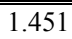 & 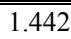 & 0.933 & $\overline{0.924}$ \\
\hline & Storage pipe: $75 \%$ & 0.998 & 0.687 & 0.359 & 0.039 & 0.631 & 0.638 & 0.145 & 0.151 \\
\hline & Storage pipe: $50 \%$ & 1.020 & 0.719 & 0.338 & 0.000 & 0.500 & 0.505 & 0.008 & 0.013 \\
\hline & Storage pipe: $25 \%$ & 1.039 & 0.752 & 0.383 & 0.029 & 0.512 & 0.517 & 0.019 & 0.025 \\
\hline & Storage pipe : $0 \%$ & 1.099 & 0.822 & 0.437 & 0.056 & 0.524 & 0.528 & 0.031 & 0.036 \\
\hline \multirow{5}{*}{ Rainfall scenario B } & Storage pipe: $100 \%$ & 1.110 & 1.083 & 0.730 & 0.382 & 1.466 & 1.451 & 0.935 & 0.919 \\
\hline & Storage pipe: $75 \%$ & 0.759 & 0.673 & 0.330 & 0.006 & 0.675 & 0.701 & 0.229 & 0.253 \\
\hline & Storage pipe: $50 \%$ & 0.920 & 0.735 & 0.386 & 0.025 & 0.500 & 0.520 & 0.035 & 0.059 \\
\hline & Storage pipe: $25 \%$ & 0.949 & 0.832 & 0.459 & 0.106 & 0.508 & 0.527 & 0.042 & 0.066 \\
\hline & Storage pipe : $0 \%$ & 0.986 & 0.947 & 0.576 & 0.212 & 0.517 & 0.535 & 0.049 & 0.072 \\
\hline \multirow{5}{*}{ Rainfall scenario C } & Storage pipe: $100 \%$ & 1.109 & 1.089 & 0.733 & 0.382 & 1.448 & 1.440 & 0.932 & 0.923 \\
\hline & Storage pipe: $75 \%$ & 0.757 & 0.674 & 0.340 & 0.000 & 0.623 & 0.631 & 0.138 & 0.143 \\
\hline & Storage pipe: $50 \%$ & 0.924 & 0.740 & 0.369 & 0.025 & 0.500 & 0.505 & 0.008 & 0.014 \\
\hline & Storage pipe: $25 \%$ & 0.926 & 0.821 & 0.467 & 0.113 & 0.513 & 0.518 & 0.020 & 0.026 \\
\hline & Storage pipe : $0 \%$ & 0.980 & 0.940 & 0.585 & 0.221 & 0.526 & 0.530 & 0.032 & 0.037 \\
\hline
\end{tabular}

A summary of the investigation results is shown in Table 5. Compared with rainfall scenario A in which inundation countermeasures using storage infrastructure for peak reduction are sufficient because the inundation control quantity is small, rainfall scenarios $\mathrm{B}$ and $\mathrm{C}$ in which the inundation control quantity is large required a combination of not only large-scale storage infrastructure but also downflow infrastructure and base reduction infiltration infrastructure to be effective in drainage zone I. For drainage zone II, the duration of continuous rainfall was short in all the rainfall scenarios and peak reduction storage infrastructure was found to be effective. From these results, we consider it important to increase the inundation control quantity across the entire area (1) using peak reduction storage infrastructure for areas at the branch line drainage zone level and for short-duration heavy rainfall, and (2) using a combination of inundation countermeasures including downflow infrastructure and storage infrastructure to upgrade the entire runoff area for heavy rainfall that continues for a long duration in areas at the main line drainage zone level. These findings are thought to validate the evaluation results obtained in our previous report (Hashimoto et al., 2012). 
Table 5 - Summary of investigation results.

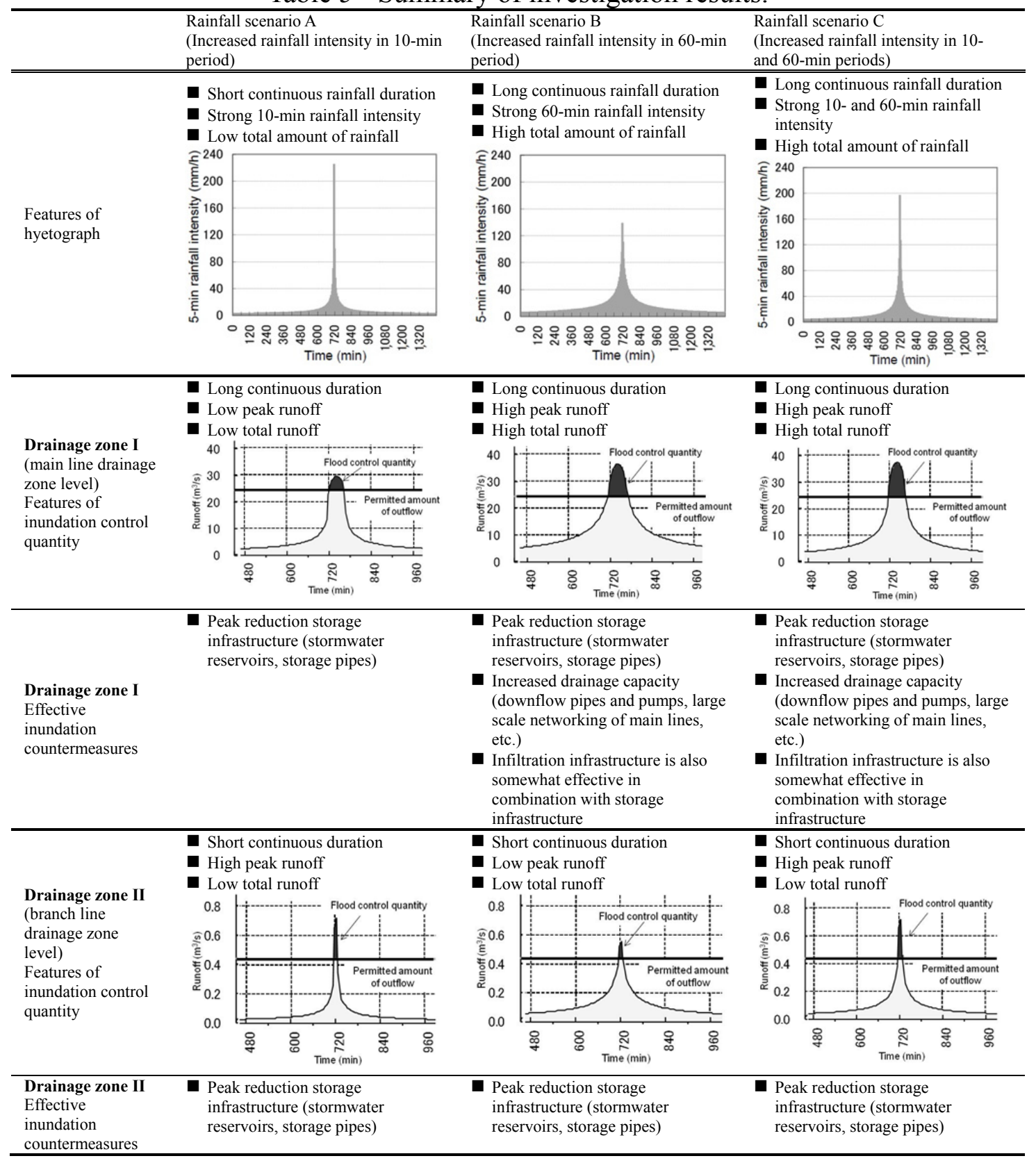

\section{EXAMPLES OF THE PROVISION OF STORMWATER STORAGE INFRASTRUCTURE IN EXISTING URBAN REGIONS}

In both drainage zone I (main line drainage zone level) and drainage zone II (branch line drainage zone level), effectiveness of stormwater storage infrastructure was suggested. In order to effectively prepare for increased heavy rain in the future, it is considered important to continue to upgrade stormwater storage infrastructure. The following are examples of stormwater storage systems provided by local governments as inundation countermeasure systems.

(1) Underground storage pipes

One method, cited a number of times as an example, is the placement of large storage 
pipes underground. A benefit of this type is that even where there is no land appropriate for aboveground storage, space can be ensured to store a vast quantity, under a road for example. It simplifies ensuring optimum installation locations or countermeasure quantities needed according to the analysis of inundation occurrence. However, it has taken a long period of time of about 10 years to provide some facilities of this kind and the construction cost of each project is relatively high.

(2) Underground storage ponds

Storage ponds have often been constructed under city-owned land or under parking lots. This type can store a huge quantity of stormwater. However, it is difficult to construct one unless this is done at the same time as buildings are constructed and when other developments are carried out aboveground. Large-scale storage ponds are also constructed under roads in the upstream region of rivers as river water measures (river projects).

(3) Surface storage in parks and other locations

Parks and schoolyards are infiltration districts found in almost all urban regions where they can be used as storage areas during heavy rainfall, so they are effective comprehensive inundation countermeasures in cities. They are also presumably cheaper than large storage systems, but they require approval of the park manager or school authorities.

(4) Storage in paddy fields

In cities whose suburbs include paddy field districts which can be used for storage, it is possible to use the existing paddy fields as storage facilities. They are not expensive, but the use of paddy fields must be in accordance with the use of the owner.

\section{COLLECTION OF CASES OF FACILITIES THAT UTILIZE STORMWATER}

In recent years, stormwater storage infrastructure has been provided not only as inundation countermeasures, but also to respond to droughts, to save resources, to save energy, and to prevent disasters. So we have collected case examples on facilities, operated by local governments, that utilized stormwater in order to promote the future provision of stormwater storage infrastructure and to utilize water resources more effectively. This section reports on progress in cataloguing case examples on facilities that utilized stormwater and in creating a database of facilities that utilized stormwater.

\section{Annual amount of stormwater used for each purpose}

In our previous report (Hashimoto et al., 2012), the purposes of use for stormwater in approximately 150 facilities were catalogued based on the number of facilities for a specific purpose. In this report, the purposes of use for stormwater were catalogued according to the annual amount of stormwater used, based on the data from 59 facilities (6 local governments) where the annual amount of stormwater use was known from among the collected cases (Fig. 4). The storage capacities of the various facilities ranged from $8 \mathrm{~m}^{3}$ to $2,000 \mathrm{~m}^{3}$. As with the results obtained in the previous report, the largest use of stormwater was for toilets and the next largest use was for sprinklers. In $30 \%$ of the facilities that utilized stormwater for toilets, the annual amount of stormwater used was less than $250 \mathrm{~m}^{3}$. By comparison, in $50 \%$ of the facilities that 
utilized stormwater for sprinklers, the annual amount of stormwater used was less than $250 \mathrm{~m}^{3}$. This suggests that stormwater for sprinklers is used at facilities where the annual amount of stormwater used is relatively small.

\section{Creation of a database of stormwater utilization systems}

Based on the data collected in this research on facilities that utilized stormwater, work is progressing upon creation of a database, employing Google Maps, for the facilities that utilize stormwater (Fig. 5). The locations of the facilities are displayed as icons, and a photograph of the facility together with the purpose of use, storage capacity, annual amount of stormwater used, timing when usage starts, and other information are displayed by clicking the icon for a facility. In the future, we plan to promote the improvement of stormwater storage infrastructure and the efficient utilization of water resources within each local government.

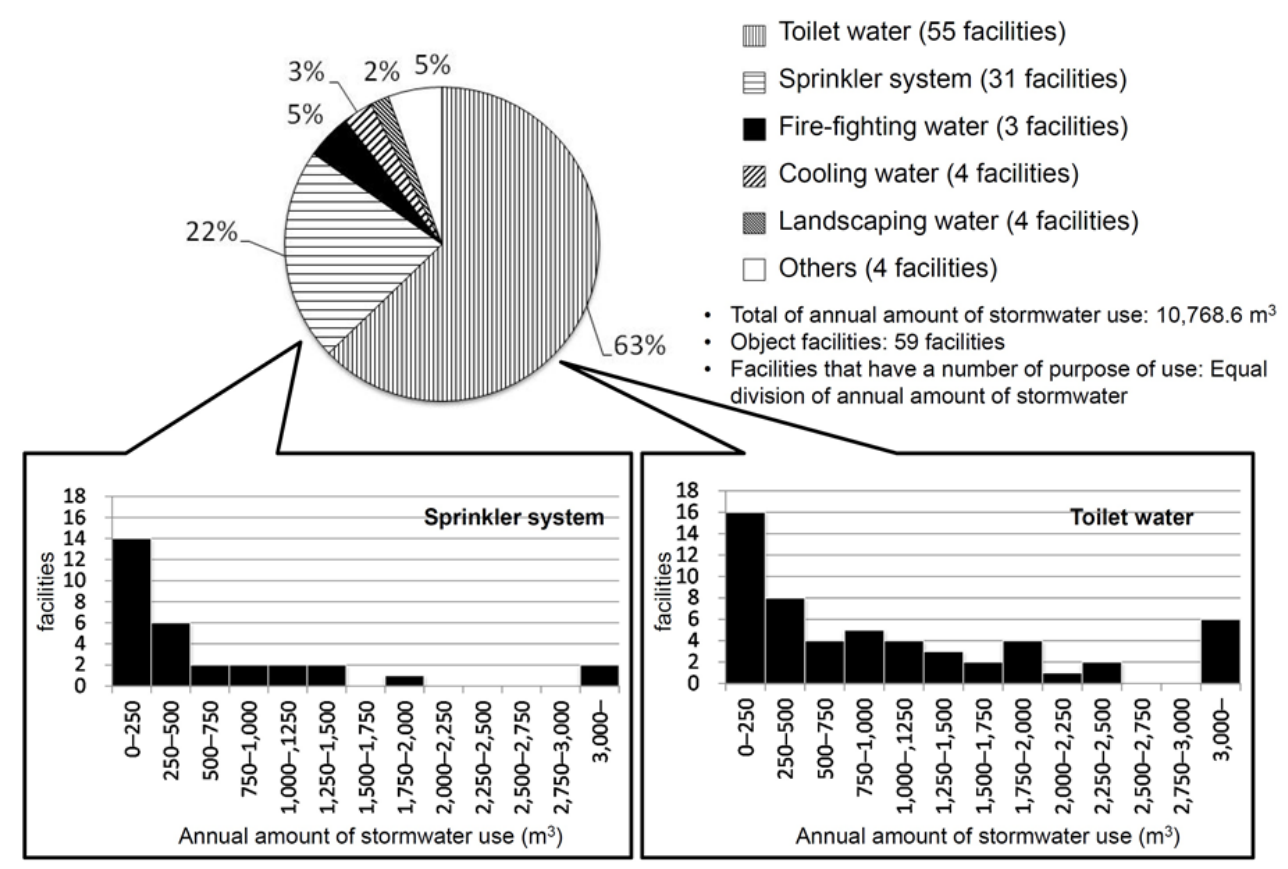

Fig. 4 - Result of cataloguing the purpose of use for stormwater based on the annual usage.

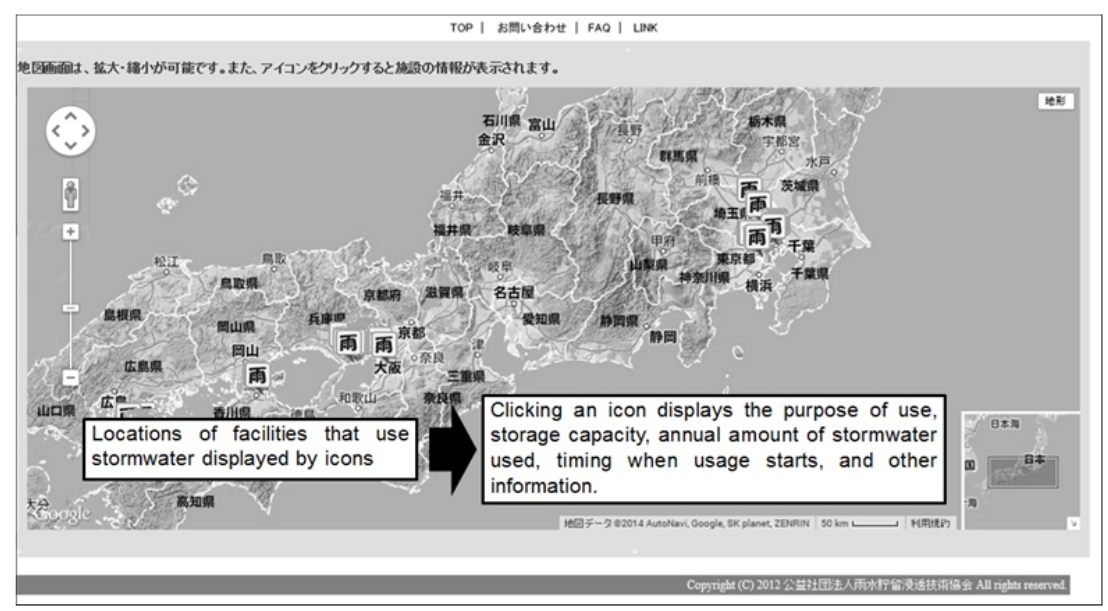

Fig. 5 - Database of stormwater utilization systems. 


\section{CONCLUSIONS}

From the results of the case study using simulated drainage zones, the details of the inundation countermeasures to be implemented should be investigated based on the characteristics of the rainfall and the area. On the basis of these results, we are proceeding with investigations into improving the planning of inundation countermeasures.

We are working to continue expanding the data in the database of facilities that utilized stormwater.

\section{ACKNOWLEDGEMENT}

The authors are deeply grateful to all members of local governments who cooperated with this research, and Association for Rainwater Storage and Infiltration Technology that cooperated with the creation of a database of facilities that utilized stormwater. A part of this research is supported by Core Research for Evolutional Science and Technology (CREST) Program "Innovative Technology and System for Sustainable Water Use" of Japan Science and Technology Agency (JST).

\section{REFERENCES}

Abe Y., Tsubokawa T., Matsuba H. and Morita H. (2011) Investigative research on measures for the mitigation of damage caused by localized torrential rainfall. Proceedings of WEFTEC $2011\left(84^{\text {th }}\right.$ Annual Water Environment Federation Technical Exhibition and Conference), Los Angeles, USA.

Abeyama K., Tanokura M. and Morita H. (2010) Technique measures by sewage to localized torrential rain. Proceedings of $5^{\text {th }}$ CECAR (Civil Engineering Conference in Asian Region), Sydney, Australia.

Hashimoto T., Shigemura H. and Yokota T. (2012) The Effects of Future Increases in Heavy Rain on Measures for the Prevention of Inundation in Urban Areas, Proceedings of 9UDM ( $9^{\text {th }}$ International Conference on Urban Drainage Modelling), University of Belgrade, Serbia.

JMA (2007) Climate Change Monitoring Report 2006. Japan Meteorological Agency. http://ds.data.jma.go.jp/tcc/tcc/products/gwp/CCMR2006/ (accessed on March 13, 2008).

Kanae S., Oki T. and Kashida A. (2004) Changes in Hourly Heavy Precipitation at Tokyo from 1890 to 1999. J. Meteorol. Soc. Jpn., 82(1), 241-247.

Kashiwai J., Tsuchiya S. and Ishigami T. (2008) Projection of Future Storm Rainfall Intensity Affected by Global Climate Change -Analysis of GCM20 Model Simulation Results -. Technical note of NILIM No. 462, NILIM (National Institute for Land and Infrastructure Management), Tokyo, Japan. (in Japanese) 